\title{
Los framers en serio: \\ el originalismo y su impacto en \\ la interpretación constitucional ${ }^{* *}$
}

\section{Taking Framers Seriously: The Originalism and its Impact in the Constitutional Interpretation}

\section{RESUMEN}

El presente artículo se relaciona con la interpretación de la Constitución, particularmente de lo que algunos teóricos han denominado el "originalismo". De esta forma, serán objeto de estudio tanto el contexto histórico en que este movimiento surgió, como los factores que lo propiciaron. En el desarrollo de esta labor, se advertirá que existen distintas formas de entender lo que el originalismo significa, y que no necesariamente todos los partidarios de esta corriente entienden la interpretación jurídica de la misma forma. Finalmente, se hará referencia a las principales críticas que ha recibido, sobre todo de aquellos que consideran que la Constitución debe ser entendida como un instrumento vivo, que debe adecuarse a las necesidades de cada sociedad.

PALABRAS CLAVE

Originalismo, interpretación, función judicial, Constitución viviente, tribunales.

\section{ABSTRACT}

The present article is related to the interpretation of the Constitution, particularly what some theorists have named as "originalism". In this way, is important to study the historical context in which this movement emerged,

* Profesor de Historia Constitucional Peruana y Derechos Fundamentales en la Universidad de San Martín de Porres. Asesor del Tribunal Constitucional del Perú. Miembro de la Asociación Peruana de Derecho Constitucional. Ha sido profesor de Derecho Constitucional Comparado y Teoría Constitucional en la Universidad Nacional Mayor de San Marcos y en la Academia de la Magistratura del Perú.Contacto: opazo@ pucp.pe. orCID: https://orcid.org/00000002-0482-2410.

** Recibido el 9 de junio del 2020, aprobado el 31 de agosto del 2020.

Para citar el artículo: Los framers en serio: el originalismo y su impacto en la interpretación constitucional. En Revista Derecho del Estado, Universidad Externado de Colombia. N. ${ }^{\circ} 48$, enero-abril de 2021, 341-369.

DOI: https://doi.org/10.18601/01229893.n48.12 
as well as the factors that led to it. In the development of this work, it will be noticed that there are different ways of understanding what originalism means, and that not necessarily all the supporters of this current understand the legal interpretation on the same way. Finally, reference will be made to the main criticisms it has received, especially from those who consider that the Constitution should be understood as a living instrument, that should be adapted to the needs of each society.

\section{KEYWORDS}

Originalism, interpretation, judicial function, living Constitution, courts.

\section{SUMARIO}

Introducción. I. El tiempo y la Constitución. II. El originalismo y su impacto en la interpretación de la Constitución. III. Críticas a las corrientes originalistas: principales frentes de ataque. Conclusiones. Bibliografía

\section{INTRODUCCIÓN}

El 1. ${ }^{\circ}$ de abril de 2001, Anne Marie Thus y Helene Faasen celebraron el primer matrimonio entre dos mujeres de toda la historia. Curiosamente, esta boda (junto con otras realizadas este mismo día) se realizó cerca de la estatua que había sido elaborada en homenaje a Baruch Spinoza, y que tiene una inscripción con la siguiente frase: "El propósito del Estado es la libertad". Esa libertad, a la que se refirió Spinoza en pleno siglo XVII, ¿habrá abarcado la posibilidad que dos personas del mismo sexo contraigan matrimonio? Hasta buena parte del siglo xx, existía un importante nivel de consenso respecto de la idea que el matrimonio era exclusivamente entre parejas de distinto sexo.

El debate se vuelve aún más problemático en aquellas sociedades que, como la estadounidense, cuentan con textos constitucionales de antigua data, ya que en estos casos se configuraría lo que Josep Aguiló ha denominado "el gobierno de los muertos", el cual se caracterizaría por hacer prevalecer la voluntad de las generaciones pasadas sobre las actuales. En efecto, en esta clase de casos surgen distintas preguntas: ¿el hecho que el matrimonio homosexual no haya sido siquiera concebido al momento de elaborar la Constitución, impide que las generaciones venideras lo reconozcan como legítimo a partir del mismo texto?, ¿tienen los jueces contemporáneos competencia para "actualizar" el texto constitucional y, de esta forma, impedir la prevalencia de la voluntad de los muertos, o es una labor que solo le compete al pueblo y sus representantes? Una vez que estas dudas son afrontadas, surge una adicional -y no por ello menos grave-, consistente en la posibilidad de descifrar el contenido esa dicha voluntad. 
En este artículo intentaremos abordar todos estos aspectos, lo cual se realizará a propósito del debate, que se ha desarrollado tanto en la doctrina como en el ámbito judicial, sobre el denominado "originalismo". Evidentemente, para realizar esta labor no solo intentaremos definir lo que debe entenderse por ese término, sino que también se analizarán distintas cuestiones vinculadas con esta corriente, como ocurre con el famoso debate entre los "vivos" y los "muertos", la supuesta imposibilidad de la judicatura de actualizar la Constitución para las sociedades actuales, y los problemas que se derivan de vivir con un texto constitucional que no ha sido pensado necesariamente para las generaciones actuales.

No pretendo, ni creo que resulte posible hacerlo, cerrar el debate respecto de los distintos conflictos y discusiones que ha generado la denominada corriente originalista, la cual, por cierto, cuenta con distintos enfoques. Me conformo con que se adviertan los retos que en una sociedad democrática plantea la idea de respetar, de manera irrestricta, la voluntad de generaciones pasadas que no tuvieron la posibilidad de imaginar los cambios que existirían en el mundo contemporáneo.

Los tiempos cambian, y con ellos también se actualizan los contenidos de los derechos fundamentales de la persona. Esto nos lleva a iniciar este artículo con una serie de reflexiones en torno al tiempo y el rol que el mismo desempeña en la Constitución.

\section{EL TIEMPO Y LA CONSTITUCIÓN}

En una conocida carta dirigida a James Madison, Thomas Jefferson escribía que "ninguna sociedad puede hacer una constitución perpetua, ni tan siquiera una ley perpetua. La tierra pertenece siempre a la generación viviente: pueden, por tanto, administrarla, y administrar sus frutos, como les plazca, durante su usufructo" ${ }^{1}$. Las reflexiones del reconocido estadista norteamericano plantean una duda que ha sido considerada crucial para los constitucionalistas: ¿cómo debe enfrentar la Constitución el reto de hacer coexistir a generaciones con distintas concepciones de lo correcto? Esto es, ¿qué debe hacerse en caso que la voluntad y el pensamiento de las generaciones pasadas sea distinta a la de las generaciones actuales?

En efecto, el tiempo es esencial para el derecho constitucional, el cual suele poner en conflicto al gobierno de los vivos en contra del de los muertos. Si lo primero prevalece, entonces es prácticamente nula la voluntad de los creadores del texto constitucional (o al menos de una importancia accesoria), ya que la Constitución habría pasado a ser una máquina con voluntad propia,

1 Extraído de: Moreno, G. El control jurisdiccional de constitucionalidad.La experiencia estadounidense como paradigma del activismo judicial. En Anuario de la Facultad de Derecho, vol. XXIX, 2011, p. 372. 
y su misión esencial sería afrontar los retos que en la actualidad se plantean. $\mathrm{Si}$, por el contrario, es importante lo segundo, entonces la Constitución es un documento sacro, cuyos apóstoles y principales autoridades serían los creadores del mismo texto.

En este último escenario, no sería posible que un ente de poder constituido lleve a cabo la actualización de la Constitución, por lo que se demandará que sean "los vivos" los que hagan prevalecer su voluntad a través de los mecanismos que el propio texto habilita, pero nunca atribuyendo al documento significados que sus creadores no pensaron. Si la adaptación del texto no se realizara de esta forma, sostienen los partidarios del originalismo, entonces la labor de los jueces u operadores devendría en antidemocrática, ya que estarían usurpando competencias que no les corresponden, y actuando, más que en contra de la voluntad popular, por encima de ella, con todas las consecuencias que ello acarrea.

Ahora bien: muchas de las discusiones en torno al originalismo se desarrollan en un terreno fértil en aquellas sociedades que cuentan con textos constitucionales relativamente antiguos. En la actualidad existen varios países que se rigieron con constituciones de, por lo menos, cien años de antigüedad, siendo el caso más representativo el de los Estados Unidos de América. En el caso europeo también se encuentran distintas experiencias en las que diversos países contaron con constituciones de considerable antigüedad, a las cuales solo añadieron una serie de reformas para adecuarlas a las necesidades actuales.

Sin embargo, esta antigüedad no debe ser percibida con malos ojos; por el contrario, estimo que son documentos que han sido elaborados con un importante nivel de mesura y generalidad, características centrales para que un documento pueda amoldarse a distintas generaciones. Como bien ha graficado Peter Haberle, en referencia a la Constitución de Estados Unidos, adoptada en el lejano siglo XVIII, "su antigüedad es una prueba de su juventud eterna, una muestra de su capacidad de renovación"2.

Se podría afirmar, entonces, que una constitución antigua no necesariamente contendrá cláusulas que hubiesen caído en desuso, sino que es un documento que ha sabido contrarrestar los problemas de interpretación con un texto lo suficientemente flexible como para hacer convivir distintas concepciones políticas y culturales. Es este curioso fenómeno de ser antigua y vigente al mismo tiempo lo que vuelve bastante interesante a la Constitución. En todo caso, es difícil imaginar a una norma, llamada a ser suprema, con un período temporal reducido. Como bien expresa Fioravanti, y que estimo refleja los problemas en torno al tiempo y la norma normarum,

2 HäBERLE, P. Tiempo y Constitución. Ámbito público y jurisdicción constitucional, Lima, Palestra, 2017, p. 25. 
[u]na constitución que no se preocupe de estos aspectos, cuya pretensión de durar sea débil, en la que sean débiles en todo caso las barreras colocadas frente a una repentina modificación, o que no esté suficientemente defendida de la posibilidad de la entrada en vigor de normas opuestas a ella, ve en efecto muy empañado su carácter de norma fundamental ${ }^{3}$.

Así, la vocación de permanencia es consustancial a la idea misma de Constitución. Sin ella, este documento solo se presenta como una solución temporal de los grandes conflictos de una sociedad. Pero la norma fundamental es más que eso, pues se encarga de realizar los grandes trazos en un ordenamiento jurídico, y, con ello, de enfrentar los más complicados retos que entraña la convivencia democrática. Si no es capaz de ello, nada la distingue de una ley aprobada por un órgano constituido, la cual se encuentra sometida a los vaivenes de las mayorías parlamentarias.

Es este constante intercambio entre lo antiguo y lo moderno lo que ha generado que el debate en torno a la interpretación constitucional sea particularmente llamativo. En muchas ocasiones esto ha generado una dicotomía entre originalistas y evolucionistas. Esto ha supuesto que sean examinadas como corrientes antagónicas, por lo que cada una de ellas pugna por cuestionar las características centrales de la otra. Curiosamente, ello, lejos de debilitarlas, las ha fortalecido, y por esto en algunos casos los propios tribunales de justicia han recurrido a los padres fundadores (framers, en el derecho estadounidense) para interpretar la norma normarun, y en otras han dejado atrás su voluntad para adecuarla a las necesidades propias de las sociedades actuales.

Es también preciso decir que un importante sector de la doctrina otorga una considerable relevancia a la voluntad de los creadores del derecho, y esto no solamente se advierte en el derecho interno. Así, por ejemplo, la Convención de Viena sobre el Derecho de los Tratados de 1969 cuenta con un criterio de interpretación que se remite a los denominados "trabajos preparatorios", los cuales contienen la voluntad de las personas que discutieron el texto final de un convenio internacional. Del mismo modo, durante un considerable tiempo se desarrolló el debate entre las posiciones que enfrentaban la voluntad "del legislador" a la voluntad "de la ley", lo cual suponía determinar si era más importante proteger la voluntad de las personas que elaboraron la ley, o el hecho de considerar que las normas, por lo general, deben afrontar situaciones originariamente no previstas en sus textos por sus redactores. $Y$ estas discusiones son más frecuentes de lo que se cree.

Es por lo hasta aquí expuesto que el originalismo tiene una importante y al mismo tiempo problemática relación con la Constitución, ya que plantea, desde su esencia, una pregunta crucial para los operadores del aparato de justicia:

3 Fioravanti, M. Constitucionalismo. Experiencias históricas y tendencias actuales, Madrid, Editorial Trotta, 2014, p. 81. 
¿la Constitución debe ser entendida tal y como fue concebida por sus framers o creadores?, ¿o es consustancial a la idea de la Constitución la posibilidad de actualizarse a las condiciones actuales? Si esto último es cierto, ¿esta operación la debe realizar un órgano judicial o el pueblo mismo a través de los mecanismos de participación ciudadana? Es aquí en donde se advierte, con bastante notoriedad, el impacto que el tiempo tiene en la idea misma de Constitución.

\section{EL ORIGINALISMO Y SU IMPACTO EN \\ LA INTERPRETACIÓN DE LA CONSTITUCIÓN}

El impacto del tiempo en el derecho constitucional ha generado que se preste una particular atención a la corriente originalista. Ahora bien: el originalismo no es una cuestión que solo deba interesar a los filósofos políticos o a los académicos, ya que tiene una influencia práctica que no se debe menospreciar, y esto no solo por el notable impacto que ha tenido en importantes estudiosos del derecho constitucional, sino porque, en algunas ocasiones, sus postulados se han reconocido en la misma norma suprema. Un ejemplo bastante gráfico se dio en Turquía, lugar donde, bajo la figura de Mustafa Kemal Atatürk, se implementó la Constitución de $1982^{4}$. En el preámbulo de este texto se ha reconocido expresamente que la Constitución se encuentra "en la línea del concepto de nacionalismo y las reformas y principios introducidos por el fundador de la República de Turquía, Atatürk, el líder inmortal y héroe sin rival”. Esta no es una simple invocación a una figura nacional, es una remisión expresa a su pensamiento al momento de interpretar las cláusulas constitucionales.

Otro caso bastante curioso en el que esto se puede advertir es el de Estados Unidos, país en el que, según los cálculos de Melvyn Durchslag, entre 1986 y el año 2002, esto es, en un período de dieciséis años, la Corte Suprema Federal citó El Federalista en noventa oportunidades, lo cual significó un aumento del $42 \%$ respecto de los dieciséis años anteriores ${ }^{5}$. Como bien se sabe, esta obra reúne un conjunto de ensayos elaborados por pensadores bastante notables de la época en que se ratificó la Constitución de Estados Unidos, a fin de explicar a la ciudadanía las bondades del documento que se estaba por implementar.

Es importante destacar que el escenario estadounidense se encuentra especialmente marcado por el debate en relación con el impacto de la corriente originalista en la interpretación de la Constitución. En efecto, como se indicó con anterioridad, esta línea de pensamiento encuentra un terreno fértil de discusión en las sociedades que se rigen por documentos de una considera-

4 VAROL, O.The Origins and Limits of Originalism: a Comparative Study. En Vanderbilt Journal of Transnational Law, n. ${ }^{\circ}$ 44, 2011, p. 1259.

5 Durchslag, $M$. The Supreme Court and the Federalist Papers: Is There Less Here Than Meets the Eye? En William \& Mary Bill of Rights Journal, n. ${ }^{\circ}$ 14, 2005, p. 295. 
ble antigüedad, ya que plasman, en mejor medida, el clásico debate entre la voluntad de las generaciones vivas respecto de las pasadas.

Esto se ha podido advertir, particularmente, en algunos fallos de la Corte Suprema Federal que interpretaron cláusulas constitucionales aprobadas en el siglo XVIII, como fue el caso de la Segunda Enmienda ${ }^{6}$. Al respecto, son bastantes conocidos los recurrentes inconvenientes que se han presentado en los Estados Unidos a propósito del uso de armas de fuego, lo cual se encuentra avalado por la propia Constitución. Sin embargo, lo que en realidad inquietó a los académicos fue la interrogante respecto del significado que debía adscribírsele a la Segunda Enmienda: ¿esta cláusula debe interpretarse en función de los propósitos por las que fue adoptada en el siglo XVIII?, ¿es indispensable dejar a un lado las razones históricas y examinar si es que, en la actualidad, el derecho a portar armas es un derecho constitucional?

Este asunto fue dilucidado en la conocida sentencia Dictrict of Columbia $v$. Heller, fallo en el que la Corte precisó los alcances de la Segunda Enmienda. En ese pronunciamiento, se examinaba una ley del Distrito de Columbia que prohibía la posesión de armas de fuego de corto alcance. La demanda había sido interpuesta por Dick Heller, un oficial de policía que había presentado una solicitud para registrar un arma que iba a mantener en su casa. Solicitaba que, en aplicación de la Segunda Enmienda, se levantara dicha prohibición. La mayoría de magistrados le dio la razón, y procedió a invalidar la ley aprobada. En todo caso, lo llamativo del pronunciamiento son las opiniones separadas de los jueces, las cuales dejan ver sus posiciones (en algunos casos originalistas) en torno a la interpretación de la Constitución. Como precisa Solum, lo resuelto en Heller tendrá implicaciones en lo que respecta al originalismo como una teoría académica de la intepretación, por un lado, y como un componente de la práctica constitucional, por el otro ${ }^{7}$. De hecho, la dividida votación en este caso demostró que el originalismo puede tener serios problemas de coherencia, ya que, desde posturas originalistas, algunos magistrados llegaron a conclusiones distintas que otros que también lo eran ${ }^{8}$.

De lo hasta aquí expuesto, es evidente el notorio impacto que el originalismo, en caso de asumirse como un criterio hermenéutico apropiado, genera en la comprensión de la Constitución. Sus postulados, lejos de refugiarse únicamente en reductos académicos, han sido trasladados también a los fallos de los tribunales, lo que refleja que es una corriente que debe ser tomada en

6 Esta disposición, como se conoce, establece que "[s]iendo necesaria una milicia bien organizada para la seguridad de un Estado libre, el derecho del pueblo a poseer armas no será infringido".

7 Solum, L. District of Columbia v. Heller and originalism. En Northwestern University Law Review, n. ${ }^{\circ}$ 103, 2009, p. 980.

8 Un estudio interesante que explora los problemas del originalismo a propósito de este fallo se puede consultar en: Tushnet, M. Heller and the New Originalism. En Ohio State Law Journal, vol. 69, 2008. 
serio. Tampoco debe ignorarse que, en muchas oportunidades, las cortes de justicia también suelen recurrir a la voluntad de los framers con el propósito de identificar la interpretación que deba otorgársele a una cláusula constitucional que contiene instituciones que no han sido objeto de mayor desarrollo en el mismo texto 9 . Se advierte, pues, que la voluntad de los framers no es algo que los tribunales hayan desechado, al menos no de antemano.

Esta forma de entender la norma suprema se encontraría respaldada, según Richard Kay, en dos grandes valores: la certeza y la legitimidad ${ }^{10}$. Conforme expone este autor, el originalismo, que él asocia con las intenciones primigenias del constituyente, es certero debido a que permitiría identificar límites precisos para el accionar del poder público, lo cual se condice con la fórmula del rule of law. Por otro lado, tiene legitimidad desde el momento en que las limitaciones al actuar de ese poder tienen que provenir de una fuente apropiada para dictaminar leyes que aten a esos mismos funcionarios, y ese valor político puede lograrse mediante el originalismo.

Sin embargo, antes de detallar la influencia que esta corriente ha ejercido en importantes sectores de la doctrina, es importante tener una noción sobre lo que el denominado "originalismo" implica. Como resulta evidente, no todos han entendido necesariamente lo mismo cuando se ha hablado de él, y ello obedece a que esta corriente tiene, como ocurre en muchos casos, distintas aristas.

De hecho, Lawrence Solum, advirtiendo esta situación, ha indicado que para hablar de originalismo es necesario comprender lo que abarca este concepto. En ese sentido, plantea que existen cuatro ideas centrales ${ }^{11}$ para poder identificarlo en sus distintas vertientes: (1) el significado lingüístico del texto constitucional debe basarse en la época en que cada disposición fue aprobada; (2) el significado constitucional debe basarse en la gramática, sintaxis, y, en general, el uso del lenguaje de la gente de la época en que la disposición fue aprobada, y no tanto por la intención de los constituyentes; (3) el texto no es un simple símbolo, por lo que el significado original de la disposición constitucional tiene fuerza vinculante; (4) debe diferenciarse entre "interpretación" y "construcción constitucional", por lo que, mientras a la primera le concierne esclarecer el significado lingüístico del texto, a la segunda le corresponde analizar el efecto legal que el texto genera para el intérprete.

9 Un debate interesante se presentó, en el caso peruano, a propósito de la denominada "cuestión de confianza". Sobre esta institución, el texto constitucional de 1993 contenía pocas o nulas referencias respecto de sus límites. A fin de dilucidar los alcances de la cuestión de confianza, el fallo del Tribunal Constitucional peruano efectúa, en distintos pasajes de la sentencia, diversas referencias a las intervenciones del abogado Enrique Chirinos Soto, uno de los congresistas que tuvo una activa participación en la elaboración de la Constitución de ese año. Ver: Tribunal Constitucional del Perú. Expediente 0006-2018-PI, fundamentos 62, 73 y 86.

10 KaY, R. "Originalist” values and constitutional interpretation. En Harvard Journal of Law \& Public Policy, n. ${ }^{\circ}$ 19, 1996 p. 335.

11 Fleming, J. Are we all originalists now? I hope not! En Texas Law Review, n. ${ }^{\circ}$ 91, 2013, p. 1787. 
De este modo, el originalismo es, en realidad, una fuente de la cual provienen distintos enfoques. Los más conocidos son los que han sido denominados como "textualistas" e "intencionalistas". En el caso de los primeros, como su nombre lo dice, intentan derivar cualquier significado de la Constitución de los propios términos empleados en ella. En esta clase de casos es por lo demás evidente que el documento, como ocurre en el resto del derecho, no tendrá todas las soluciones para los casos que se examinen. En estos escenarios, los que defienden esta postura son de la idea que debe respetarse la concreción del contenido que realiza el legislador democrático. Por otro lado, en el caso de los intencionalistas, ellos buscan desentrañar la voluntad o propósito de los que elaboraron el texto. Como puede apreciarse, dentro de los que, en un sentido macro, pueden ser considerados "originalistas", existen distintas formas de interpretar la Constitución. Se trata, así, de un movimiento con divisiones en su interior.

Recientemente se ha resaltado el surgimiento de un nuevo originalismo (new originalism), y que es al que se hace referencia en la definición de Solum. En realidad, esta tendencia, como ha ocurrido generalmente con este enfoque, también cuenta con distintas voces dentro de su interior. Se suele identificar a Keith Whittington como uno de sus más grandes representantes, ya que este autor desarrolló las bases principales de este modelo, y que se relacionan con la idea del significado público original y la tesis de la construcción como complemento del proceso de interpretación ${ }^{12}$.

Sobre esto último, se ha considerado un punto neurálgico de este movimiento diferenciar entre la interpretación -entendida como una actividad direccionada a identificar el significado lingüístico de un texto- y la construcción, la cual es concebida como la labor de trasladar el significado semántico a reglas jurídicas, sobre todo en aquellos supuestos en los que el texto es vago ${ }^{13}$. Esta separación, de hecho, ha permitido al nuevo originalismo encontrar herramientas interesantes para rebatir las críticas respecto de su presunta incompatibilidad con principios como el del stare decisis, y no han faltado autores que inviten a que se critique esta corriente por su presunta responsabilidad en aceptar fallos como Brown vs. Board of Education, ya que, según se sostiene, esos ataques solo cuestionan la peor versión del originalismo, y no terminan por advertir que casi todos los nuevos originalistas están de acuerdo con esta decisión judicial ${ }^{14}$.

12 Whittington, K. New Originalism. En The Georgetown Journal of Law \& Public Policy, vol. 2, 2004.

13 Solum, L. District of Columbia v. Heller and Originalism. En Northwestern University Law Review, vol. 103, 2009, p. 973.

14 Se dice, en esencia, que el fallo de Brown no es contrario al significado público original de la Decimocuarta Enmienda, ya que la idea de la construcción permite adoptar una regla de implementación distinta a la de "separados pero iguales". Esto no significa que el nuevo originalismo esté facultado de apartarse del significado original, sino que revela que es posible brindar 
De todo lo hasta aquí expuesto, justo es decir que el denominado "originalismo" ha enfrentado distintos problemas incluso desde su interior. Así, dentro de este mismo movimiento, algunos consideran que la labor interpretativa abarca aquello que el legislador "quiso decir", mientras que, por otro, están aquellos que estiman que lo único que le corresponde al operador es desentrañar aquello que el legislador efectivamente promulgó. Si de por sí el originalismo, que se fundamenta en lo efectivamente promulgado por el legislador, es problemático, la situación es aún más complicada si es que intentamos extraer lo que el legislador -o constituyente- "quiso decir". Sobre esto, Antonin Scalia, al criticar la postura vinculada con lo que el legislador "quiso decir", anota que "gobernar a través de una intención no expresada es igualmente tiránico. Es la ley la que gobierna, no la intención del legislador [...]. Los hombres pueden querer lo que ellos quieran: pero son sólo las leyes que ellos promulgan aquello que nos obliga" 15 .

La crítica que se realiza a esta vertiente del denominado "originalismo" se relaciona, pues, con la imposibilidad, tanto jurídica como fáctica, de conocer cómo es que el legislador, de aun encontrarse presente, hubiese resuelto los problemas sociales actuales. Ahora bien: este problema no se reduce únicamente al originalismo. La labor de interpretar la Constitución, para muchos pensadores, ha sido muchas veces reducida a la voluntad particular de los magistrados que ejercen control jurisdiccional, y que solo traducen sus preferencias políticas. Si a esto se añade la dificultad del salto temporal respecto de los constituyentes, la problemática es exponencial.

En este orden de ideas, y como ya se había indicado a propósito de la explicación de lo que suponía el new originalism, otro asunto que ha generado importantes grietas dentro de esta corriente es el relacionado a la forma de abordar lo que se ha denominado "la dificultad del stare decisis" ${ }^{16}$. La esencia del argumento gira en torno a la aparente incompatibilidad entre este principio -fuertemente arraigado en el derecho estadounidense- y la corriente originalista, ya que pueden presentarse escenarios en los que una interpretación ajena al significado o la intención original del texto -realizada "por

un nuevo entendimiento de esa cláusula siempre y cuando se encuentre dentro de lo permitido por ella. Ver: BARNETT. R. Trumping precedent with original meaning: not as radical as it sounds. En Georgetown Law Faculty Publications and other works, Constitutional Commentary 22, 2005, pp. 260-261.

15 Scalia, A. Los tribunales del common law en un sistema de Derecho continental. En: Gutman, Amy. Una cuestión de interpretación. Los tribunales federales y el derecho, Lima, Palestra Editores, 2015, p. 80.

16 No sorprende que un originalista como Barnett haya sostenido que el originalismo tiene una especial dificultad con el precedente. Para examinar con mayor profundidad las grietas que este debate ha dejado dentro de los propios originalistas, se recomienda consultar: Peters, C. Precedents in the United States Supreme Court, Nueva York, Springer, 2014. Particularmente, consultar el capítulo 9, el cual aborda la complicada relación entre la doctrina del precedente y el originalismo. 
error" por la Corte Suprema- se hubiera consolidado en la jurisprudencia a través de la doctrina del precedente. Esto podría generar la sensación que, por el transcurso del tiempo, sea la lectura de la Constitución formulada por este tribunal la que prevalezca sobre el posible significado original, lo que colocaría al stare decisis en contra del originalismo.

Otra cuestión que genera no pocos debates se relaciona con el contexto en que esta corriente de pensamiento surgió. Al respecto, es posible notar que no existe un momento exacto en que surgió el originalismo como forma de interpretación constitucional, pero lo que sí es relativamente claro es que fue un fenómeno que empezó a expandirse a propósito de los críticos de la labor de la famosa Corte Warren, y, en esto, desempeñaron un importante rol el antiguo presidente Richard Nixon y el conocido juez Roberto Bork, al cual se le recuerda por su postulación -sin éxito- al cargo de magistrado de la Corte Suprema Federal de los Estados Unidos. Este último intentó trasladar la idea de los "principios neutrales" de Wechsler al campo de la interpretación constitucional, ya que, según su forma de comprender las cosas, los jueces han demostrado bastante libertad para trasladar sus propios principios a las sentencias, por lo que la interpretación no sería más que una forma en la que los jueces buscan adecuar la actividad hermenéutica a su propia idea de justicia ${ }^{17}$. Según entiende, estos problemas pueden ser combatidos a través de la remisión al significado original de la Constitución.

Es importante destacar, sobre este punto, que el originalismo no es, a diferencia de otros conceptos o herramientas existentes en el derecho comparado, una creación de origen jurisprudencial. De hecho, los primeros debates sobre la conveniencia de su adopción surgieron lejos de los estrados judiciales. Sobre ello, se ha recordado ${ }^{18}$ que fue particularmente durante el gobierno de Ronald Reagan en el que, a propósito de reflexionar sobre la filosofía judicial, se convocó a pensadores como Edwin Meese, Robert Bork o Antonin Scalia. Ello originó la posterior fundación de la Federalist Society, entidad que tenía como principal misión promover importantes discusiones sobre lo que significaba el originalismo y cómo este impactaba en la función judicial ${ }^{19}$.

17 Whitesell, S.L. The Church of Originalism. En University of Pennsylvania. Journal of Constitutional Law, n. ${ }^{\circ} 16,2014$, p. 1541.

18 Whittington, K. Originalism: a critical introduction. En Fordham Law Review, vol. 82, n. 2 2, 2013, pp. 375 y 376 .

19 La importancia de ser o no originalista pudo advertirse en el marco de la postulación de Robert Bork a la Corte Suprema Federal de Estados Unidos, sobre todo por las preguntas formuladas por el Senado. Este mismo pensador va a sostener que la Federalist Society, a diferencia de la American Civil Liberties Union (ACLU), se va a caracterizar por estar integrada por liberales y conservadores que tenían como único foco de preocupación el creciente activismo de dicho tribunal. Otra diferencia que, según Bork, era posible advertir respecto de la ACLu era que la Federalist Society no fija posiciones sobre asuntos públicos ni participa en litigios. Ver, sobre la opinión de Bork: Post, R. y SIEGEL, R. Originalism as a political practice: the Right's Living Constitution. En Fordham Law Review, vol. 75, 2006, p. 561. 
Ahora bien: para entender el motivo del surgimiento del originalismo es imprescindible comprender la magnitud de los pronunciamientos de la Corte Warren. Como bien nota Christopher Wolfe, durante la presidencia de Earl Warren distintas disposiciones constitucionales fueron tratadas "como generalidades vagas que hacían poco más que enunciar principios que el Tribunal tenía que especificar mediante el procedimiento de equilibrar distintos intereses" 20 . De ello se desprende que la jurisprudencia de esa Corte partió de la premisa que la Constitución contiene distintas cláusulas abstractas, pero corresponde al operador jurisdiccional valorar los intereses en juego, siendo esto más importante que la "revelación" de la voluntad del constituyente. Es sintomático que, en esta época, se haya expedido la famosa sentencia Brown vs. Board of Education, la cual hizo una lectura de la Decimocuarta Enmienda que se hubiera apartado de lo que pensaban la mayoría de personas en el siglo XVIII.

De este modo, el originalismo surge como una reacción al notorio rol que estaba asumiendo el Tribunal Supremo Federal de los Estados Unidos para interpretar las disposiciones constitucionales. Tiene bastante sentido que esto haya ocurrido precisamente en dicho país, ya que este se caracteriza por sus importantes brechas temporales. De hecho, las primeras enmiendas se remontan a 1791, y algunas de las más importantes, al siglo XIX. Es, pues, bastante natural que la discusión respecto del significado de la cláusula en el contexto de su aprobación haya tenido sentido en dicho país.

En realidad, justamente este es otro de los aspectos que hace reflexionar respecto del impacto del originalismo en el derecho constitucional. Jon Elster muestra cómo es que en muchas oportunidades las constituciones fungen como actos de sometimiento de la voluntad de los vivos a la de los muertos, y expresa que "[c]rear una Constitución que ate o restrinja a las generaciones futuras puede también -en un sentido amplio- ser visto como un acto de autorrestricción, a saber, si se espera que los agentes políticos del futuro alberguen las mismas razones para desear estar restringidos que albergaba la generación fundacional" 21 .

En el derecho constitucional, el debate en torno al originalismo no es pueril. En muchas ocasiones es determinante para entender el significado y los alcances de la Constitución. Es más, podría decirse que es crucial desde el momento en que se emplea para resolver los conflictos generados a propósito de las grandes controversias actuales (tales como el aborto, la eutanasia, el matrimonio entre personas del mismo sexo o la manipulación genética). Un ejemplo bastante gráfico de esta importancia medular se advirtió en el caso

20 Wolfe, C. La transformación de la interpretación constitucional, Madrid, Civitas, 1991, p. 353.

21 ELSTER, J. Ulises desatado. Estudios sobre racionalidad, precompromiso y restricciones, Barcelona, Gedisa, 2002, p. 119. 
Obergefell vs. Hodges, en el cual la Corte Suprema Federal de los Estados Unidos, por una mayoría de cinco contra cuatro, determinó que debía reconocerse el matrimonio entre personas del mismo sexo como una obligación que se derivaba de la Decimocuarta Enmienda, que reconoce el principio de igualdad. Las opiniones en contra demuestran una importante referencia a lo que se pensaba cuando se aprobaron las enmiendas. Así, en su voto disidente, el juez Antonin Scalia expresó que

cuando la Decimocuarta Enmienda fue ratificada en 1868, cada Estado limitaba el matrimonio a un hombre y una mujer, y nadie duda de la constitucionalidad de hacerlo. Esto resuelve estos casos. Cuando se trata de determinar el significado de una vaga disposición constitucional -como el «debido proceso legal»o la «igual protección de las leyes»-, es incuestionable que el Pueblo que ratificó dicha disposición no la entendió como prohibir una práctica que seguía siendo universal e incontrovertida años después de la ratificación. No tenemos base para derogar una práctica que no está expresamente prohibida por el texto de la Decimocuarta Enmienda $[\ldots]^{22}$.

Del razonamiento del justice es posible notar que el principal criterio que ha valorado para determinar si la no regulación del matrimonio entre personas del mismo sexo resulta inconstitucional es el relacionado con el estado de la cuestión en el momento en que la enmienda fue aprobada, esto es, en 1868. De esta forma, razona que, al aprobarse esta enmienda, se encontraba dentro del ideario de la época el hecho de considerar usual el que el matrimonio como institución no englobaba la posibilidad de una eventual unión entre parejas del mismo sexo. De este modo, esta clase de entendimiento de la institución del matrimonio, que era la generalmente compartida en el momento en que se aprobó esta enmienda, genera que la no incorporación de esta clase de uniones no sea contraria a la Constitución.

De todos modos, siempre es importante advertir que diversos autores han demostrado posturas un poco más conciliadoras entre el presente y el pasado. Esto supone reconocer que aunque no es un criterio absoluto para determinar la postura de un juez respecto de alguna cláusula constitucional, la opinión de los fundadores es ciertamente relevante para poder determinar lo que la Constitución quiso reconocer en realidad. Esto no implica, evidentemente, que este reconocimiento sea absoluto, sino que permite encontrar importantes pautas para acercarse al verdadero significado de la norma suprema. En ese sentido, es evidente que los autores de la Constitución tenían ciertos puntos de vista morales frente a algunas preguntas particulares, y que incluso emplearon

22 Información extraída de: Delgado, D. Obergefell contra Hodges: la sentencia de la Corte Suprema de los Estados Unidos sobre el matrimonio entre personas del mismo sexo. En Revista de Derecho Político de la UNED, n. ${ }^{\circ}$ 99, 2017, p. 349. 
distintos conceptos dotados de valores para mantener, cuestionar o eliminar determinadas prácticas, por lo que merece una especial atención de nuestra parte lo que ellos estaban tratando de decir ${ }^{23}$.

Es importante agregar que el originalismo no suele actuar solo. En efecto, no es una corriente que justifique sus decisiones con la sola apelación al pasado, sino que, además, encuentra un importante punto de legitimidad en la voluntad popular. En efecto, en no pocas oportunidades los jueces originalistas han dejado bastante clara la idea de que no es que se opongan a que se incorporen algunos avances en las sociedades contemporáneas, pero sí cuestionan que sean los jueces los responsables de desarrollar dicha labor. La frase del justice Robert es bastante ilustrativa en este punto, ya que se encarga, en su voto disidente, de dejar en claro que "este Tribunal no es una Asamblea Legislativa. Si el matrimonio homosexual es una buena idea no nos concierne. Bajo la Constitución, los jueces tienen poder para decir lo que la ley es, no lo que debería ser"24.

Esta línea de razonamiento, en realidad, se encuentra bastante marcada por la distinción que en su momento efectuó Jeremy Bentham, quien hizo referencia al derecho como es (what the law), del derecho como debería ser (what it ought to be), y que, a su vez, distingue una teoría expositiva del derecho a través de la primera forma, y una censoria mediante la segunda ${ }^{25}$. Por ello, es bastante común afirmar que la filosofía política apunta al derecho como debería ser. Y es precisamente aquí donde los jueces sienten que deben marcar una adecuada separación entre sus convicciones personales y lo que, efectivamente, reconoce la norma fundamental de la nación. No es su función, según ellos lo entienden, trasladar sus propias preferencias al momento de interpretar la Constitución al resto de la sociedad, ya que es ella misma la que tiene la función de actualizar su contenido a través de los cauces contenido en su propio cuerpo normativo.

La expresión del juez presidente Roberts refleja que el originalismo difícilmente, puede ser empleado en solitario para justificar alguna decisión, sobre todo si ella versa sobre el reconocimiento de principios o derechos constitucionales. Así, el voto disidente se encarga de enfatizar que no es competencia del Poder Judicial establecer lo que la ley (y se entendería que también la Constitución) debería reconocer, sino aquello que efectivamente tutela. De este modo, no son trascendentales -desde el punto de vista de la justicia- las concepciones que, sobre la idea del bien, tengan los magistrados supremos. Lo fundamental es entender que no es su rol el colocar frases o

23 Notes. Original meaning and its limits. En Harvard Law Review, n. 20, 1997, p. 1299.

24 Delgado, D. Obergefell contra Hodges: la sentencia de la Corte Suprema de los Estados Unidos sobre el matrimonio entre personas del mismo sexo. En Revista de Derecho Político de la UNED, n. ${ }^{\circ} 99,2017$, p. 347.

25 Viola, F. Rule of Law. El gobierno de la ley, ayer y hoy, Lima, Palestra, 2017, p. 132. 
términos que el pueblo no ha autorizado de manera directa o a través de sus representantes legítimamente electos.

Es así que el originalismo suele respaldarse en una concepción de la función judicial según la cual los operadores jurisdiccionales deben dejar que las grandes controversias sean decididas por las mayorías parlamentarias o por el pueblo mismo, y esto, como no podía ser de otro modo, también supone restringir el activismo judicial. Esto es aún más notorio en los casos que comprometen a las fibras más sensibles de alguna sociedad democrática. De este modo, consideran que es el pueblo mismo -o, en su defecto, el Parlamento en su condición de representante- el legitimado para efectuar las reformas que sean necesarias para adaptar el documento de los fundadores a las circunstancias actuales. Así, según consideran, sus propias concepciones del bien no son relevantes al momento de administrar justicia, ya que el rol del operador jurídico es interpretar la Constitución de conformidad con lo que se entendía en el contexto en que ella se aprobó.

De este modo, cualquier incorporación o reforma no es una labor que al juez le corresponda, ya que debe ser un ente con la misma legitimidad que el poder constituyente el que actualice los contenidos normativos. Se trata de evitar aquello que Edouard Lambert denominó "el gobierno de los jueces", o la existencia de un cuerpo aristocrático judicial que, independientemente de los intereses o el sentir del pueblo, haga prevalecer sus propias convicciones al resto de integrantes de la comunidad. De hecho, este autor nos hizo recordar que en 1912 un libro empezó a circular abogando por el retorno de la independencia del poder legislativo, cuyo título, bastante significativo para revelar el propósito del movimiento, era Nuestra oligarquía judicial ${ }^{26}$. Mucho del originalismo tiene que ver con la visión restrictiva de la función judicial para interpretar la Constitución.

Evidentemente, no ha sido una corriente exenta de críticas. En el siguiente apartado se procederá a analizar cuáles han sido los principales cuestionamientos que ha recibido.

III. CRÍTICAS A LAS CORRIENTES ORIGINALISTAS:

PRINCIPALES FRENTES DE ATAQUE

El originalismo, más allá de que se compartan sus postulados, ha reactivado importantes debates que involucran al rol de los jueces en el Estado constitucional, los métodos de interpretación y el papel que desempeña la Constitución en una sociedad democrática. Sin embargo, ello no impide notar que existen distintos puntos que pueden ser controvertidos respecto de sus pilares fundamentales. Estimo que las principales críticas se resumen en los siguientes puntos: (1) la Constitución no es un instrumento para petrificar la 
voluntad "de los muertos"; (2) existen limitaciones cognitivas para identificar la voluntad colectiva de un órgano colegiado; (3) entendido de manera estricta, el originalismo resta importantes atribuciones a los jueces, lo cual posterga derechos de los grupos minoritarios. Corresponde, en consecuencia, examinar cada uno de estos puntos.

(1) La idea de la "living Constitution" y su incidencia en la sociedad actual

Uno de los principales autores que han trabajado la noción de living Constitution es David Strauss. En la cubierta del libro (que también lleva por título The living Constitution) de este jurista puede apreciarse una constitución escrita en un pergamino, y un árbol por encima de él. Como bien anota Balkin, el propósito de esta cubierta radica en resaltar cómo es que el texto constitucional crece y trasciende al documento primigeniamente adoptado, por lo que existen distintas ramas que crecen en muchas direcciones y que, en algunos casos, brillan como estrellas por su impacto en el ordenamiento ${ }^{27}$.

La idea de la Constitución como un instrumento vivo trae consigo una cuestión trascendental, que tiene que ver con la consideración de la norma suprema como un producto que se aparta de lo que en su momento quisieron sus creadores para convertirse en una herramienta para la pacificación social. En ese sentido, no tendría mucha coherencia reconocer a una constitución que no tenga vocación futurista, ya que lo contrario podría suponer que esté condenada de antemano a verse relegada y abrogada frente a la presencia de crecientes y nuevas demandas sociales.

De esta forma, si se entiende que la Constitución tiene la cualidad de una máquina con voluntad propia, puede concluirse que la intención de los constituyentes, aunque puede ser tomada en cuenta al momento de interpretar la norma suprema, no se erige como una suerte de metacriterio que deba ser considerado incuestionable por parte del operador jurisdiccional. Esto implicaría el hecho de que las palabras del constituyente no se desarrollan en una realidad inalterable y no expuesta al cambio social. De esta manera, a la autoridad jurisdiccional le debe importar examinar cómo es que, en la actualidad, los principios y los derechos reconocidos en la Constitución deben reaccionar frente a los nuevos usos del poder. Esto puede implicar, en muchas ocasiones, que incluso deba apartarse expresamente de lo que en su momento pensaron -o que quizás nunca estuvieron en la posibilidad de conocer- los redactores del texto constitucional.

El debate entre "vivos y muertos" se cerraría, de esta forma, a favor de los primeros. Al fin y al cabo, son ellos los que se benefician o perjudican de las políticas públicas o decisiones judiciales que, tras interpretar la Constitución,

27 BALKIN, J. The roots of the Living Constitution. En Boston University Law Review, $\mathrm{n}{ }^{\circ}$ 92, 2012, p. 1128. 
formulan distintos entes del Estado. No tendría mucho sentido, por lo demás, que un texto de este nivel de importancia sea adaptado para regular la vida de una sola generación de personas. Sobre este punto, Thomas Jefferson ha sido enfático al sostener que el mundo pertenece a la generación viviente, por lo que consideraba absurdo cualquier intento de emplear la Constitución como herramienta para hacer prevalecer la voluntad de los muertos ${ }^{28}$.

Ahora bien: es importante precisar que para la "Constitución viviente" el contenido de la misma norma suprema no se reduce únicamente a lo dispuesto en el texto normativo. De hecho, este documento suele actualizarse con la interpretación que los jueces hacen de ella, o incluso cuando el legislador, interpretando de manera progresiva su contenido, adopta distintas leyes de desarrollo. En ese sentido, autores como Laurence Tribe han brindado importantes pautas para poder destacar cómo es que especialmente la autoridad judicial identifica lo que él ha denominado una suerte de "Constitución invisible", la cual, según se entiende, va mucho más allá de su texto escrito ${ }^{29}$. A estas ideas se sumaron otras que postulaban la legitimidad de las cortes de justicia -ante la inactividad del resto de poderes- para actualizar el conjunto de principios y de normas que la Constitución contiene para adaptarla a los nuevos tiempos ${ }^{30}$.

Por otro lado, es también importante precisar que la idea de Constitución viviente es invocada, por lo general, en dos contextos. En primer lugar, para consolidar una línea de pensamiento mayoritario que coincide en que una institución no puede ser entendida como lo era antes; y, en segundo lugar, para romper las reglas del pasado cuando estas ya no sean pasibles de ser invocadas en la coyuntura contemporánea, independientemente del sentir mayoritario. En este sentido, Ronald Kahn ha afirmado ${ }^{31}$ que cuando los cambios en la sociedad son simbióticos con los principios y doctrinas de los derechos, entonces los casos emblemáticos perdurarán en el tiempo; pero, por otro lado, cuando las construcciones empleadas en casos anteriores ya no son sostenibles, los casos emblemáticos permiten su modificación sustancial o, por qué no, su vuelco absoluto.

Estimo que, en el primer caso, existe una elevada probabilidad que el leading case adoptado no suponga una alteración importante del tejido social, y solo consolidaría una tendencia ya aceptada en la sociedad. En

28 Información consultada en: RuIPÉREZ, Javier. Algunas consideraciones sobre la reforma constitucional. En Revista de Estudios Políticos, n. ${ }^{\circ}$ 75, 1992, p. 236.

29 Ver, al respecto: TrIBE, L. The Invisible Constitution, Nueva York, Oxford University Press, 2008.

30 Ver, al respecto, el estudio preliminar de Pablo de Lora en: Waluchow, W. Una teoría del control judicial basada en el Common Law, Madrid, Editorial Marcial Pons, 2009, p. 14.

31 Kann, R. Originalism, the living Constitution, and Supreme Court decision making in the twenty-first century: explaining Lawrence vs. Texas. En Maryland Law Review, n. ${ }^{\circ}$ 67, 2007, p. 27. 
estos casos, probablemente las leyes hayan caído en desuetudo, y la función del juez solamente sea la de terminar de liquidar una regulación obsoleta. Esto puede ocurrir, por ejemplo, en una sociedad en la que se penaliza la homosexualidad, pese al mayoritario y actual respaldo del derecho al libre desarrollo de la personalidad, lo que conduce a que, en la práctica, nadie sea sancionado por ese delito en un Estado particular. De hecho, sorprende que en un país como Estados Unidos recién en el año 2003 se afirmase que las leyes que sancionaban la sodomía eran incompatibles con la Constitución, pese a que para ese momento histórico la mayoría de estadounidenses consideraba absurda esta represión por parte del Estado. En efecto, en el momento en el que el Tribunal Supremo Federal resolvió el caso Lawrence vs. Texas, solo catorce estados de la Federación contenían esta clase de disposiciones en el Código Penal, lo cual demuestra que no era una tendencia mayoritaria cuando la Corte tuvo la oportunidad de pronunciarse.

El segundo caso es mucho más problemático. En este escenario, se invoca la interpretación evolutiva en un contexto en que la sociedad, al menos mayoritariamente hablando, no se encuentra de acuerdo con la decisión adoptada por el juez constitucional. En el caso colombiano, por ejemplo, cuando la Corte Constitucional resolvió su emblemático caso respecto del matrimonio entre personas del mismo sexo, un considerable sector de la población se oponía a su legalización. En aquella oportunidad, este tribunal precisó que

[1]a interpretación jurídica es evolutiva y como tal se adapta a los contextos que plantea la realidad. Una interpretación sistemática basada en el "derecho viviente", y en procura de los derechos de las minorías, no admite la existencia de dos clases de matrimonio, enviando un mensaje de inferioridad a algunas personas, pues ello comporta un trato diferenciado y desproporcionado fundado en la orientación sexual que quebranta los derechos a la libertad, a la dignidad humana y a la igualdad [Corte Constitucional de Colombia. SU-214/16].

La oposición entre el sector mayoritario colombiano y lo resuelto por la Corte Constitucional se traducirá, en un futuro no muy lejano, en un conflicto entre los parlamentos y los tribunales de justicia, ya que los primeros pugnarán porque se respete la voluntad popular, mientras que los segundos abogarán, seguramente, por la aplicación inmediata del principio de igualdad y no discriminación. En este supuesto, es muy probable que los originalistas manifiesten que la corte está intentando imponer su visión del principio de igualdad a la población colombiana, más aún si la Constitución de 1991 y la Convención Americana sobre Derechos Humanos no concibieron, en el momento en que fueron aprobadas, la figura del matrimonio homosexual.

Entregar la interpretación de la Constitución a un colegiado de juristas puede tener muchos puntos a favor, pero también otros en contra. Cuando la Corte Suprema de Estados Unidos conoció el caso Brown vs. Board of Education tenía 
claro lo que implicaba una correcta interpretación del principio de igualdad, y es algo que los estadounidenses reconocen al día de hoy. Sería importante examinar cuánto hubiese demorado el Congreso Federal en adoptar una ley que expresamente prohíba la segregación en las escuelas. En esta oportunidad el tribunal no falló, pero es probable que en otros casos sí lo haga, y es en estos escenarios donde surge la pregunta respecto de quién es más aceptable que se equivoque, si el pueblo mismo o un cuerpo de funcionarios no electos por él. De hecho, la sombra del caso Dred Scott vs. Sandford, aquel fatídico caso que excluyó de protección legal a los esclavos con una visión bastante restrictiva del concepto de ciudadano, siempre va a estar presente, sobre todo porque les dio fuertes argumentos a los seguidores del originalismo para sostener sus planteamientos respecto de la interpretación de la Constitución. De hecho, autores bastante conocidos como Jeremy Waldron han apelado a pronunciamientos como los de Lochner v. New York con el propósito de argumentar que no en todos los casos han sido los tribunales de justicia los mejor posicionados para interpretar las libertades ${ }^{32}$.

Sin embargo, y más allá de lo hasta aquí expuesto, estimo que los jueces, muchas veces, tienen una labor que, por lo general, termina siendo bastante impopular, lo cual no quiere decir que sea una que se ejerza en contra de la plena vigencia de los derechos. Para tales efectos, es pertinente hacer una analogía entre la función del médico y la labor de una autoridad judicial que administra justicia. En efecto, cuando padecemos de algún mal tenemos un fundado temor de escuchar los diagnósticos médicos, y seguramente quisiéramos solamente oír a aquel doctor que nos diga que nuestro estado de salud es óptimo, pero no por ello podemos simplemente ignorar lo que un especialista tiene que decir sobre la materia que conoce a la perfección. Es probable que algo similar ocurra con el derecho constitucional, el cual demanda de los tribunales de justicia el adecuado conocimiento de lo que el derecho en realidad demanda.

De este modo, es a ellos a quienes corresponde, ante la inactividad del resto de órganos estatales, velar por la conformidad de las prácticas e instituciones con los derechos fundamentales, los cuales no hacen sino reflejar necesidades básicas de las personas. Sobre ello, Jerzy Wróblewski sostiene que "a la interpretación legal se le exige que adapte el derecho a las necesidades de la vida social para hacerlo más adecuado a ésta. Esta adecuación es el valor máximo de la ideología dinámica de la interpretación legal. El significado de la regla legal no es, por tanto, ningún hecho del pasado conectado por vínculos ficticios con la voluntad del legislador histórico. De

32 Waldron destaca que, entre 1885 y 1930, los tribunales estatales y federales invalidaron aproximadamente 150 normas jurídicas que regulaban las relaciones de trabajo y las condiciones laborales. Ver: Waldron, J. Derechos y Desacuerdos, Madrid, Marcial Pons, 2005, p. 344. 
ser así, el derecho resultaría un gobierno de los muertos sobre los vivos" ${ }^{\prime 3}$. La tarea del derecho, entonces, sería tratar de sobreponerse a las cadenas del pasado para liberar al presente.

Para finalizar, no puede dejar de mencionarse que tampoco han faltado autores que, como Randall Kelso, cuestionen el hecho de que los mismos originalistas intenten imponer una estructura metodológica para interpretar la Constitución que, probablemente, los framers no hubiesen deseado para su Constitución en el futuro ${ }^{34}$. Si una persona tuviese la posibilidad de entrevistar a los grandes estadistas del siglo XVIII en Estados Unidos seguramente obtendría, como mayoritaria respuesta, que una constitución no puede ser concebida para las generaciones pasadas, sino para el contexto en que se desenvuelve, tal y como lo planteó el mismo Jefferson.

(2) La dificultad cognitiva para identificar la voluntad de órganos colegiados

Una de las más constantes críticas que hace en contra del originalismo se relaciona con la imposibilidad de conocer la voluntad de los constituyentes, sobre todo al tratarse de un órgano colegiado. Similares cuestionamientos se hacen para tratar de determinar el empleo del lenguaje o los usos y costumbres de la época. Si en la actualidad es bastante complicada la labor de desentrañar lo que desea la denominada "voluntad popular", en tanto concebida como agregados de preferencias individuales, el asunto es mucho más problemático cuando nos remitimos a lo que estimaron las generaciones pasadas, sobre todo si ha transcurrido una considerable cantidad de tiempo, ya que ello borra importantes registros históricos.

Así, uno de los inconvenientes que se le atribuye a esta corriente se traduce en la falta de fuentes documentales que permitan extraer la voluntad de los constituyentes o creadores de la Constitución. Esto no solo se relaciona con aquellos casos en los que no exista algún soporte documental respecto de las sesiones de algún órgano colegiado, sino que también tiene que ver con el hecho de que los denominados framers puedan haber expresado una opinión sobre una importante cantidad de asuntos de interés público, pero no de aquel que es objeto de interpretación por las autoridades actuales.

Del mismo modo, otro inconveniente que se relaciona con los problemas cognitivos tiene que ver con la dificultad de encontrar la posición de un órgano de naturaleza colegiada. Si es compleja la labor de determinar el sentido interpretativo que uno de los constituyentes sostuvo respecto de una temática en particular, mucho más delicada es la labor cuando se trata de un

33 WróBlewsKi, J. Constitución y teoría general de la interpretación jurídica, Madrid, Civitas Ediciones, 2001, p. 76.

34 Kelso, R. Contra Scalia, Thomas, and Gorsuch: originalist should adopt a living constitution. En University of Miami Law Review, n. ${ }^{\circ}$ 72, 2017, p. 174. 
órgano que no cuenta, muchas veces, con una opinión unificada sobre algún tema en especial. La línea entre intentar esta labor, y la de intentar descifrar lo que el constituyente "quiso decir" es, en realidad, bastante delgada, por lo que existe un fuerte riesgo de distorsionar y atribuir al pasado cosas en las que, en realidad, nadie pensó.

Una cuestión bastante interesante ocurre con aquellos órganos colegiados de reciente data. En ese sentido, algunos se preguntan si resultaría viable realizar alguna consulta respecto de lo que los constituyentes consideran sobre un problema que, en su momento, no fue objeto de discusión, lo cual garantizaría, según se considera, el respeto a la voluntad primigenia de ese órgano colegiado. Aquí se puede presentar una curiosa paradoja, ya que nada impediría que luego de un tiempo un integrante de una asamblea constituyente alterara su opinión respecto de alguna materia de interés público, pese a lo inicialmente indicado según el diario de debates.

Sin embargo, es bastante curioso el constante intercambio académico que se ha realizado respecto de la posibilidad de interpretar la Constitución intentando colegir la voluntad de las personas involucradas en la elaboración de dicho documento. De manera recurrente, tanto liberales como conservadores se han acusado mutuamente de intentar imponer una agenda de valores a la sociedad. En el caso de los ataques de los conservadores a los liberales, se les imputa imponer una suerte de agenda de "grupos de izquierda", y asî insertar, sin participación de la voluntad popular, los principios que son de su simpatía. De hecho, una de las principales críticas que a inicios de los años ochenta se realizó a la Corte Warren fue que la jurisprudencia progresista de este tribunal "nada tenía que ver con la Constitución" ${ }^{35}$. Del mismo modo, los liberales acusan a los conservadores de utilizar el originalismo como una excusa para perpetuar prácticas antiguas que no se condicen con las formas de vida en las sociedades actuales.

En todo caso, una importante crítica es que, más allá del hecho de que una persona pueda no simpatizar con las corrientes originalistas, ello no puede conducir a vaciar de contenido el significado histórico que tiene la Constitución. En un interesante ensayo, los profesores Pojanowski y Walsh, adaptando una conocida frase propia del constitucionalismo europeo respecto de la inmediata sucesión de los reyes, han sostenido que la "interpretación evolutiva" muchas veces intenta modificar el "alma" de la Constitución pese a dejarla en el mismo cuerpo, lo que en realidad es la creación de un nuevo ser. En ese sentido, estiman que en la actualidad se ha mutado la idea de una constitución con vocación de permanencia y eternidad por una que muere y renace todos los días, por lo que, ante la afirmación de que "la Constitución

35 Post, R. and Siegel, R. Originalism as a political practice: the rights's living Constitution. En Fordham Law Review, n. ${ }^{\circ} 75,2006$, p. 555. 
ha muerto", solo resta decir “ ¡viva la Constitución!"”36. Es una crítica que no debe ser desdeñada, porque tiene que ver con la seguridad jurídica y con la propia esencia de la función judicial.

(3) La cuestión contramayoritaria y el rol de los jueces en el Estado constitucional

Finalmente, uno de los argumentos que han empleado distintos originalistas tiene que ver con la falta de legitimidad de los jueces para actualizar el contenido de la Constitución a las circunstancias actuales. Sostienen que en caso de que se desee adoptar nuevas interpretaciones respecto de los derechos reconocidos en la Constitución, ello debe ser explicitado a través del respectivo proceso de reforma constitucional, y no a través del criterio de unos cuantos jueces que, sustituyendo la voluntad del pueblo, impondrían, según afirman, la de ellos.

De este modo, la función judicial no podría suplir la voluntad originaria del constituyente, pues toda modificación trascendental de la Constitución, tal y como había sido concebida por sus creadores, no debería ser efectuada por un órgano de poder constituido. Así, los defensores de esta corriente afirmarán que, aunque ellos mismos se encuentren convencidos de que el matrimonio entre personas del mismo sexo se deriva del principio de igualdad, ellos no son los autorizados para efectuar dicho pronunciamiento, pues es imposible entender que en el siglo XIX eso hubiese sido entendido así por quienes aprobaron la respectiva enmienda. Así, ellos no estarían autorizados para imponer sus propias preferencias personales al resto de personas, pues ellos manejan una concepción del bien tan legítima como la de ellas. Solo son el pueblo mismo o sus representantes los autorizados para hacerlo.

Ciertamente, estos argumentos suenan bastante atractivos. De hecho, en la actualidad ha ganado bastante terreno lo que se ha denominado "constitucionalismo popular", que es una corriente de pensamiento que defiende la idea de que la interpretación de la Constitución debe dejar de ser un asunto propio de una suerte de aristocracia judicial para volver a formar parte de una competencia exclusiva del pueblo. De esto se deduce, como bien expone Chemerinsky, que "el control de constitucionalidad no es muy importante en la práctica para la sociedad" 37 . También hizo que Alexander Bickel acuñara, en 1962, la expresión "dificultad contramayoritaria" para englobar distintas críticas respecto del rol que los jueces ejercen frente a las decisiones adop-

36 PoJanowsKi, J. and W ALSCH, K. Enduring originalism. En The Georgetown Law Journal, n. ${ }^{\circ} 105,2016$, p. 157.

37 Chemerinsky, E. y Parker, R. Constitucionalismo Popular, Bogotá, Siglo del Hombre Editores, 2011, p. 68 
tadas por otros entes del Estado, y que reflejan los problemas para conciliar la judicial review y el gobierno por parte del pueblo ${ }^{38}$.

Advierto, sin embargo, que dejar en manos de las mayorías la interpretación y actualización de la Constitución genera no pocos inconvenientes. Si siempre se dejara en manos de la sociedad definir cuándo ella está preparada para aceptar los cambios significativos, podría generarse una innecesaria postergación de sus libertades. De hecho, en Estados Unidos, cuando se iba a decidir la que acaso sea una de las controversias más importantes que haya conocido la Corte Suprema Federal -que no es otra que el famoso caso Brown-, existía bastante rechazo a la idea de eliminar la segregación racial. Esto llevó a que el célebre Martin Luther King Jr., al momento de defender su posición, afirmara que si ellos se encontraban equivocados respecto de su entendimiento del principio de igualdad y la eliminación de la discriminación en contra de la comunidad afrodesdenciente, entonces la Constitución de Estados Unidos también lo estaba ${ }^{39}$.

De este modo, es posible afirmar que sin el control judicial de constitucionalidad de las leyes existiría un potencial riesgo de desprotección de las minorías, pues tendría que trascurrir una considerable cantidad de tiempo hasta que exista un importante nivel de consenso en una sociedad cada vez más plural sobre cuestiones jurídicas sensibles. También es importante recordar, como lo hace Richard Pildes, que aunque la labor de los tribunales de invalidar las leyes puede aparecer contra-mayoritaria, puede que sea concebida de forma mayoritaria desde un nivel más profundo de análisis, más aun cuando nada garantiza que la política trazada por el gobierno o el parlamento recoja las preferencias de los grupos más numerosos ${ }^{40}$.

En esta misma línea, Lawrence Sager ha hecho referencia al originalismo como una suerte de modelo de agencia, lo cual implica que el juez hace las veces de un agente del pasado, cuya función no radica en identificar los alcances de los principios contenidos en la Constitución, sino en excavar y encontrar la forma en que los padres fundadores o la sociedad de la época hubieran reaccionado frente a ciertos dilemas. Sobre ello, precisa que "los jueces constitucionales son colaboradores y no agentes, y se espera de ellos que soporten mucho peso y responsabilidad normativa en el proceso de detallar las cláusulas constitucionales generales y abstractas" ${ }^{41}$. Se sostiene, de esta forma, que el originalismo sería incompatible con la propia función judicial.

38 Friedman, B. The history of the countermajoritarian difficulty, Part One: the road to judicial supremacy. En New York University Law Review, n. ${ }^{\circ}$ 73, 1998, p. 335.

39 BReYer, S. Cómo hacer funcionar la democracia. El punto de vista de un juez, México D.F, Fondo de Cultura Económica, 2017,p. 101.

40 PILDEs, R. Is the Supreme Court a "Majoritarian" institution? En New York University Public Law and Legal Theory, Working Papers, 2011, n. ${ }^{\circ} 251$, p. 50.

41 SAGER, L. Juez y Democracia. Una teoría de la práctica constitucional norteamericana, Madrid, Marcial Pons, 2007, p. 38. 
Sin embargo, y a modo de reflexión final, el originalismo, incluso en sus versiones más polémicas, no debe ser relegado en el estudio del derecho constitucional. Su presencia ha generado importantes críticas a la teoría del "árbol viviente" que no deberían ser soslayadas. Sobre esto, se ha mencionado que los no-originalistas sostienen que toda interpretación es solo una cuestión de elección normativa, lo cual, en los hechos, solo significa que se rechace toda información contenida en el texto y solo se acuda al concepto desarrollado o construido por el intérprete, con la arbitrariedad que eso puede suponer ${ }^{42}$. En efecto, en muchas oportunidades, sobre todo en aquellos casos en que no se debaten cuestiones vinculadas con derechos o principios constitucionales, la voluntad primigenia del constituyente puede dar importantes luces respecto de la interpretación del texto constitucional. De hecho, la referencia a los denominados cuadernos de debates de las constituciones o a los famosos "acuerdos preparatorios" (en el caso de los tratados internacionales se puede consultar, por ejemplo, el artículo 31 de la Convención de Viena sobre el Derecho de los Tratados) como fuentes para la interpretación jurídica es bastante recurrente en la actualidad. No es, evidentemente, la forma concluyente para interpretar un texto, pero sí es una importante manera de acercarse a los orígenes de las constituciones, para, de esta forma, intentar desentrañar la lógica y el propósito de la construcción de los principios e instituciones de una sociedad. Como bien refiriera Paolo Grossi, las constituciones de la modernidad deben ser un diálogo entre los constituyentes y quienes ejercen el poder público ${ }^{43}$.

Un importante aporte, con el fin de definir con exactitud lo que debe entenderse como control de constitucionalidad, implica a su vez comprender los alcances del concepto de democracia. En efecto, la gran crítica que esta clase de fiscalización recibe tiene que ver con el apartamiento de la voluntad popular, cuyo producto principal se ve reflejado en la ley elaborada por sus representantes directos. El cuestionamiento va en el sentido de que controles de esta clase, sobre todo cuando son realizados por autoridades judiciales, devienen en actos antidemocráticos. Al respecto, Fioravanti precisa que en la actualidad la ley ya no es inatacable porque contenga la "voluntad general", sino que vale en cuanto, y solo en cuanto, realice en sí "el ideal democrático de la pacífica convivencia entre la pluralidad de las fuerzas e intereses que operen en la realidad". Es así que en una verdadera democracia no puede imperar, por sí sola, la voluntad de la mayoría, sino que esta, con el fin de sustentar su legitimidad, debe reflejar un importante espacio de diálogo y respeto por los deseos y derechos de grupos minoritarios ${ }^{44}$.

42 Barnett, R. Interpretation and Construction. En Harvard Journal of Law \& Public Policy, vol 34, n. ${ }^{\circ}$ 1, 2011, p. 71.

43 Grossi, P. La Constitución italiana como expresión de un tiempo jurídico posmoderno. En Historia Constitucional, n. ${ }^{\circ}$ 15, 2014 , p. 7.

44 Fioravanti, M. Constitución. De la antigüedad a nuestros días, Madrid, 2011, p. 158. 
Ahora bien: es importante también notar que el respeto irrestricto a la voluntad de las mayorías fue atacado desde distintos frentes. Uno de los primeros focos en los que esto se advirtió fue en el constitucionalismo estadounidense, país que se ha caracterizado por aportar la idea del control judicial al derecho constitucional. En este modelo, rápidamente se notó que la prevalencia inmediata y sin restricciones del principio democrático traería diversos problemas a la supremacía de la Constitución. Curiosamente, fue en este país en el que John Adams, quien más tarde sería presidente en los Estados Unidos, afirmó que su patria estaba viviendo bajo lo que él denominó un "despotismo democrático". En ese sentido, este autor consideró que el poder absoluto "podía recaer en un emperador o un rey igual que en una asamblea popular" 45 .

Sin embargo, también se puede imputar a ciertas tendencias originalistas -sobre todo aquellas que protegen textos constitucionales de considerable antigüedad-el hecho de que al momento de adoptar sus respectivas cartas, incurrieron en errores de legitimidad bastante graves, que en la actualidad no serían admitidos. Por ejemplo, Brest recuerda que en los debates constituyentes de 1787 la población afrodescendiente no tuvo ningún grado de participación, tal y como se presentó en las controversias a propósito de la aprobación de la Decimocuarta Enmienda. Del mismo modo, todos los debates que se suscitaron luego de la Guerra de Secesión estadounidense englobaron posiciones propias de los propietarios blancos y no de la población en su conjunto, lo cual hace notar que en las constituciones antiguas no se puede hablar propiamente del respeto a un principio democrático ${ }^{46}$. Todo esto no hace sino corroborar la idea de que remitirse a los documentos y entenderlos en el contexto en que fueron adoptados dejaría a muchos grupos en la actualidad despojados de las garantías mínimas para desenvolverse en igualdad de condiciones respecto del resto de la sociedad.

Pese a todo lo expuesto, no han faltado autores (y quizás nunca falten) que consideran que el originalismo estará siempre presente en la interpretación constitucional. En un sugestivo ensayo, Tara Smith, profesora de filosofía en la Universidad de Texas, explica que el originalismo "jamás va a morir", y ello obedece a que esta corriente cuenta con una fuerte base moral, la cual se relaciona con el hecho de que para muchas personas es más importante la fidelidad a las palabras que en su momento fueron escritas que entregarnos a las reglas fijadas por hombres simples, quienes son precisamente los jueces sentados en los banquillos ${ }^{47}$.

45 Pisarello, G. Un largo termidor. La ofensiva del constitucionalismo antidemocrático, Madrid, Trotta, 2011, p. 67.

46 BREST, P. The Misconceived Quest for the Original Understanding. En Boston University Law Review, n. ${ }^{\circ} 60,1980$, p. 230.

47 Sмітн, T. Why originalism won't die. Common mistakes in competing theories of judicial interpretation. En Duke Journal of Constitutional Law \& Public Policy, n. ${ }^{\circ}$ 2, 2007, p. 161. 
Lo que, en todo caso, sí es cierto es que la voluntad de los constituyentes es algo que debe ser tomado en serio. Esto no necesariamente para perpetuar la voluntad de personas pertenecientes a generaciones pasadas, sino también para encontrar las razones por las que en algunos casos es imprescindible dejarla de lado. Los tribunales de justicia han demostrado una importante deferencia hacia lo que quisieron los padres fundadores de la Constitución, ya que, o bien consideran las ideas que ellos tenían en relación con los derechos o las instituciones que en ella se recogen, o, en todo caso, se encargan de brindar razones para apartarse de ellas. Esto supone un intercambio que es deseable en toda sociedad democrática, ya que genera que la historia pueda también ser considerada al momento de identificar el significado de las cláusulas constitucionales.

\section{CONCLUSIONES}

El significado o la intención de los que elaboraron la Constitución son cuestiones que no deben ser dejadas de lado en la labor de aproximarse a una interpretación adecuada de la Constitución. Y, sin embargo, tampoco se le debe tomar tan en serio. Al momento de acercarse a lo que este documento quiso decir, el operador jurisdiccional debe saber discernir en qué escenarios lo que el constituyente dijo es relevante y cuándo no. La historia, pues, no debe ser desdeñada al interpretar los textos constitucionales, pues puede brindar importantes herramientas para entender su correcto alcance. Solo de esta manera es posible brindarle a la intención de los que elaboraron el documento el sitial que merece.

Por otro lado, la labor del juez constitucional radica en tener la mesura suficiente para identificar en qué escenarios es recomendable su participación activa para proteger a personas o los grupos que, en el vaivén de las mayorías, seguramente no obtendrían ninguna clase de tutela, y cuándo debe ser deferente con el legislador democrático. Sin esta importante herramienta, el juez no se diferencia del trabajador de la administración que, sin posibilidad alguna de elección, debe aplicar automáticamente la legislación. Las democracias contemporáneas demandan, según entiendo, el respeto de un elenco mínimo de libertades, y en esa importante operación los jueces no pueden quedar relegados. Esto implica que los derechos de la Constitución también deban ser tomados en serio.

Finalmente, y para dar alguna señal de la forma en que deben ser abordados casos como los de Anne Marie Thus y Helene Faasen, es importante recordar que aunque la historia es ciertamente relevante para desentreñar el significado de las cláusulas constitucionales, su rol no termina por ser determinante. Los propios originalistas, con el concepto de construcción como complemento de la interpretación, parecen ceder un poco en este punto. Difícilmente alguien en la actualidad cuestionará lo apropiado que fue el 
hecho de que, en su momento, la Corte Suprema resolviera el caso Brown de la forma en que lo hizo, y seguramente lo mismo ocurrirá en unos años con lo establecido en Obergefell. En ese sentido, es importante que, a la par que debe reconocerse el valor de la historia expresada en el texto constitucional, este último también debe demostrarse abierto y dialogante con las nuevas tendencias que pueden advertirse en la sociedad.

\section{BIBLIOGRAFÍA}

BALKIn, J. The roots of the Living Constitution. Boston University Law Review, n. $92,2012$.

BARNETT. R. Trumping precedent with original meaning: not as radical as it sounds. En Georgetown Law Faculty Publications and other works, Constitutional Commentary 22, 2005.

Barnett, R. Interpretation and Construction. En Harvard Journal of Law \& Public Policy, vol. 34, n. $^{\circ} 1,2011$.

Brest, P. The Misconceived Quest for the Original Understanding. En Boston University Law Review, n. ${ }^{\circ}$ 60, 1980.

Breyer, S. Cómo hacer funcionar la democracia. El punto de vista de un juez, México D.F, Fondo de Cultura Económica, 2017.

Chemerinsky, E. y Parker, R. Constitucionalismo Popular, Bogotá, Siglo del Hombre Editores, 2011.

Delgado, D. Obergefell contra Hodges: la sentencia de la Corte Suprema de los Estados Unidos sobre el matrimonio entre personas del mismo sexo. En Revista de Derecho Político de la UNED, n. ${ }^{\circ}$ 99, 2017.

Durchslag, M. The Supreme Court and the Federalist Papers: Is There Less Here Than Meets the Eye? En William \& Mary Bill of Rights Journal, n. ${ }^{\circ}$ 14, 2005.

ELSTER, J. Ulises desatado. Estudios sobre racionalidad, precompromiso y restricciones, Barcelona, Gedisa, 2002.

Fioravanti, M. Constitución. De la antigüedad a nuestros días, Madrid, Trotta, 2011.

Fioravanti, M. Constitucionalismo. Experiencias históricas y tendencias actuales, Madrid, Editorial Trotta, 2014..

Fleming, J. Are we all originalists now? I hope not! En Texas Law Review, n. ${ }^{\circ}$ 91, 2013.

Friedman, B. The history of the countermajoritarian difficulty, Part One: the road to judicial supremacy. En New York University Law Review, n. ${ }^{\circ}$ 73, 1998.

Grossi, P. La Constitución italiana como expresión de un tiempo jurídico posmoderno. En Historia Constitucional, $\mathrm{n} .^{\circ} 15,2014$.

HäBERLE, P. Tiempo y Constitución. Ámbito público y jurisdicción constitucional, Lima, Palestra, 2017. 
Kahn, R. Originalism, the living Constitution, and Supreme Court decision making in the twenty-first century: explaining Lawrence vs. Texas. En Maryland Law Review, n. ${ }^{\circ} 67,2007$.

KAY, R. "Originalist” values and constitutional interpretation. En Harvard Journal of Law \& Public Policy, n. ${ }^{\circ}$ 19, 1996.

Kelso, R. Contra Scalia, Thomas, and Gorsuch: originalist should adopt a living constitution. En University of Miami Law Review, n. ${ }^{\circ}$ 72, 2017.

Lambert, E. El gobierno de los jueces, Madrid, Tecnos, 2010.

Moreno, G. El control jurisdiccional de constitucionalidad. La experiencia estadounidense como paradigma del activismo judicial. En Anuario de la Facultad de Derecho, vol. XXIX, 2011.

Notes. Original meaning and its limits. En Harvard Law Review, n. ${ }^{\circ}$ 20, 1997.

Pildes, R. Is the Supreme Court a "Majoritarian" institution? En New York University Public Law and Legal Theory, Working Papers, 2011, n. 251.

Pisarello, G. Un largo termidor. La ofensiva del constitucionalismo antidemocrático, Madrid, Trotta, 2011.

Pojanowski, J. and Walsch, K. Enduring originalism. En The Georgetown Law Journal, n. ${ }^{\circ} 105,2016$.

Post, R. and Siegel, R. Originalism as a political practice: the rights's living Constitution. En Fordham Law Review, n. ${ }^{\circ}$ 75, 2006.

RuIPÉREZ, Javier. Algunas consideraciones sobre la reforma constitucional. En Revista de Estudios Políticos, n. ${ }^{\circ}$ 75, 1992.

SAGER, L. Juez y Democracia. Una teoría de la práctica constitucional norteamericana, Madrid, Marcial Pons, 2007.

Scalia, A. Los tribunales del common law en un sistema de Derecho continental. En: Gutman, Amy. Una cuestión de interpretación. Los tribunales federales y el derecho, Lima, Palestra Editores, 2015.

Sмith, T. Why originalism won't die. Common mistakes in competing theories of judicial interpretation. En Duke Journal of Constitutional Law \& Public Policy, n. 2, 2007.

Solum, L. District of Columbia v. Heller and originalism. En Northwestern University Law Review, n. $103,2009$.

Tribe, L. The Invisible Constitution, Nueva York, Oxford University Press, 2008.

Tushnet, M. Heller and the New Originalism. En Ohio State Law Journal, vol. 69, 2008.

VArol, O. The Origins and Limits of Originalism: a Comparative Study. En Vanderbilt Journal of Transnational Law, n. $44,2011$.

Viola, F. Rule of Law. El gobierno de la ley, ayer y hoy, Lima, Palestra, 2017. 
Waldron, J. Derechos y Desacuerdos, Madrid, Marcial Pons, 2005.

Waluchow, W. Una teoría del control judicial basada en el Common Law, Madrid, Editorial Marcial Pons, 2009.

Whitesell, S.L. The Church of Originalism. En University of Pennsylvania. Journal of Constitutional Law, n. ${ }^{\circ}$ 16, 2014.

Whittington, K. New Originalism. En The Georgetown Journal of Law \& Public Policy, vol. 2, 2004.

Whittington, K. Originalism: a critical introduction. En Fordham Law Review, vol. 82, n. ${ }^{\circ} 2,2013$.

Wolfe, C. La transformación de la interpretación constitucional, Madrid, Civitas, 1991, p. 353.

WRÓBLEWSKI, J. Constitución y teoría general de la interpretación jurídica, Madrid, Civitas Ediciones, 2001, p. 76. 